\title{
UBER E A LIVRE INICIATIVA
}

\author{
Renata Albuquerque Lima ${ }^{1}$ \\ Maria Eliane Carneiro Leão Mattos
}

\section{RESUMO}

No Brasil, tem-se a regulação e limitação da livre iniciativa em diversos campos. Nesse contexto, o presente trabalho visa discutir a (des)necessidade de regulação econômica no setor de transporte privado, tendo por pano de fundo o caso específico da empresa UBER. Para tanto, a metodologia utilizada tem caráter bibliográfico e qualitativo, com o objetivo de investigar quais as justificativas que têm sido apresentadas pelos que entendem como necessária a existência de regulação no setor. Do estudo concluiu-se que a conquista da iniciativa privada pela regulamentação de empresa de transporte 'público' individual, tradicionalmente representativa de um serviço de concessão do Estado, representou uma grande evolução para o país.

PALAVRAS-CHAVES: UBER. Transporte privado. Regulação econômica. Livre iniciativa. Concessão do estado.

\begin{abstract}
In Brazil, there is the regulation and limitation of free enterprise in various fields. In this context, the present work aims to discuss the (need) of economic regulation in the private transportation sector, having as background the specific case of UBER. Therefore, the methodology used has a bibliographic and qualitative character, with the objective of investigating the justifications that have been presented by those who understand as necessary the existence of regulation in the sector. The study concludes that the conquest of private initiative by the regulation of individual 'public' transport company, traditionally representative of a state concession service, represented a great evolution for the country.
\end{abstract}

KEYWORDS: UBER. Private transport. Economic regulation. Free Initiative. State grant.

\section{INTRODUÇÃO}

\footnotetext{
${ }^{1}$ Pós-Doutora em Direito pela Universidade Federal de Santa Catarina. Doutora em Direito Constitucional pela Universidade de Fortaleza - UNIFOR. Atualmente professora do Mestrado em Direito e da Graduação em Direito da UNICHRISTUS. Professora-Adjunta do Curso de Direito da Universidade Estadual Vale do Acaraú UVA. Coordenadora do Curso de Direito da Faculdade Luciano Feijão - FLF. Email: realbuquerque@ yahoo.com ${ }^{2}$ Mestranda em Direito pela Unichristus, Especialista em Processo Civil pela UNIFOR (Universidade de Fortaleza), Advogada. Email: eliane@mattosmattos.adv.br
} 
Nos dias atuais, seja no aspecto político, econômico ou social, a liberdade passou a ser discutida com prioridade. No campo econômico, em especial, a liberdade é ainda mais importante, na medida em que se polarizam escolas antagônicas de intervenção do Estado na Economia: o liberalismo econômico e o intervencionismo estatal.

Neste contexto, a livre iniciativa surge como um princípio da ordem econômica social brasileira que tem como fundamento basilar a própria ideia de liberdade. No art. 170 da Constituição Brasileira, o constituinte garantiu que "a ordem econômica" está "fundada na valorização do trabalho humano e na livre iniciativa". Portanto, um dos fundamentos da ordem econômica brasileira é, precisamente, a livre iniciativa.

Por livre iniciativa, tem-se o direito de empreender, de iniciar uma atividade econômica no Brasil, sem as limitações que a Constituição ou as leis não estabelecerem, ou seja, com liberdade. A livre iniciativa garante, dessa forma, o direito não apenas do empreendedor de iniciar uma atividade empresária no país, mas também ao próprio destinatário de escolher, entre as diversas sociedades ou tipos empresariais, aquele que melhor atende às suas necessidades.

Assim, da mesma forma como quem se dirige a uma praça de alimentação de um shopping center pode escolher entre os diversos tipos de restaurantes disponíveis, pode o consumidor brasileiro exigir, respeitadas as limitações constitucionais, os serviços que pretende utilizar dentre aqueles disponíveis. Esta ideia de livre iniciativa, que será analisada neste artigo, garante o empreendedorismo e o desenvolvimento social, permitindo ao consumidor o direito à escolha.

A despeito disso, tem-se, no Brasil, a regulação e limitação da livre iniciativa em diversos campos, a exemplo da aviação - na medida em que apenas empresas brasileiras podem realizar vôos domésticos nacionais, por força de regulação protetiva - e da telefonia empresas estrangeiras não estão autorizadas a atuar no Brasil, limitando, assim a liberdade de empreender e a liberdade de consumo.

Por este viés, se pretende discutir a (des)necessidade de regulação econômica no setor de transporte privado, tendo por pano de fundo o caso específico da empresa UBER. E, para tanto, a metodologia utilizada tem caráter bibliográfico e qualitativo, com o objetivo de investigar quais as justificativas que têm sido apresentadas pelos que entendem como necessária a existência de regulação no setor, até mesmo por questões tributárias, e dos que 
entendem possível o exercício desta atividade empresarial independentemente de regulação. Objetiva-se, ainda, expor algumas iniciativas legislativas que foram apresentadas no país a partir deste problema.

\section{O LIBERALISMO ECONÔMICO OU O INTERVENCIONISMO ESTATAL NA ATIVIDADE ECONÔMICA?}

A história nos conta que as ideias liberalistas ou intervencionistas de grandes economistas mundiais, ao longo de diversos cenários políticos e sociais, têm oscilado de acordo com o momento pelo qual passe a economia de um determinado povo.

Assim, tende-se a admitir que quando a economia vai bem, o Estado entrega esta estabilidade às próprias leis de mercado, com uma intervenção mínima, confiando na reação do que se costumou chamar 'mão invisível'3. Mas em períodos de graves crises estatais, políticas e/ou econômicas, o Estado intervém para acalmar a economia, negando as consequências do livre mercado, criando projetos (úteis ou inúteis) para assegurar à população, emprego e renda, e ao mercado, o aumento do consumo.

Em regra, são períodos de oscilação nas teses de economistas que, por terem maior ou menor poder de argumentação, irão 'praticamente' governar o mundo, ou, por suas idéias, modificar o encaminhamento que será emprestado às economias mundiais.

Assim, ocorreu, por exemplo, com o economista britânico John Maynard Keynes, que começou a adquirir fama, nos Estados Unidos, exatamente durante a grande depressão do pós-guerra, ali pelos anos trinta, Keynes defendia a ação do Estado na economia com o objetivo de atingir o pleno emprego, ou seja, defendia que, em momentos de estagnação da economia, com drástica redução da renda e do consumo, far-se-ia necessária a intervenção do Estado para equilibrar a economia. Suas ideias eram observadas sem muitas oposições, pois as pessoas passaram a desfrutar de aumento do nível de emprego no serviço público.

As ideias de Keynes passaram por diversas fases e foram precisamente definidas no seguinte estudo de Jorge Miguel Cardoso Ribeiro de Jesus (2011), sendo claro que sua visão liberal estava mais associada à sua fase inicial de pensamento, a qual, mais ao final, foi adaptada para o modelo mais conhecido, intervencionista. Nesse sentido, Jorge Miguel Cardoso Ribeiro de Jesus (2011, p. 131):

\footnotetext{
${ }^{3}$ Conceito criado por Adam Smith, considerado um dos pais da economia, que significaria, numa economia não intervencionista, a 'lei da oferta e da procura'.
} 
$\mathrm{Na}$ fase inicial, seguindo a tradição marshaliana, Keynes preconizava o liberalismo comercial e a livre circulação de capitais, aceitando a teoria quantitativa da moeda. Posteriormente, na transição da sua visão económica, apesar da predominância na variação dos níveis dos preços, as ideias pela preferência pela liquidez, da moeda como um activo, da não neutralidade da moeda bem como do facto de ser o lucro que "move as empresas já estão presentes.

Neste período - final dos anos 1930, sob a batuta das ideias de Keynes, o controle governamental deu ao sistema bancário, que se encontrava com reservas excessivas, liquidez, segurança e estabilidade, porque passaram a usufruir de uma vasta e lucrativa área para investimento.

Cabe salientar algumas das importantes máximas no pensamento de Keynes em sua fase mais conhecida: a)a defesa da intervenção estatal na economia, especialmente nas áreas em que onde a iniciativa privada não tem capacidade (ou não deseja) atuar; b) a defesa de ações políticas voltadas para a proteção da economia; c) a defesa de medidas econômicas estatais que visem garantir o pleno emprego, por meio do equilíbrio entre demanda e capacidade de produção; d) ao Estado caberia o papel fundamental de estimular as economias nos momentos recessão e crise econômica; e) a intervenção do Estado deve ser realizada por meio do cumprimento de uma política fiscal para que não ocorra o aumento da inflação (JESUS, 2011).

Friedrich August Von Hayek, cuja obra acadêmica iniciou sua repercussão em 1927, permaneceu com suas ideias respeitadas, mas não seguidas até 1974, quando ganhou o Prêmio Nobel de Economia. Indiscutivelmente, foi e ainda hoje é assim considerado, o maior opositor de Keynes, a quem atribui a fama não necessariamente às ideias (posto que delas discordava frontalmente), mas a uma grande sensibilidade oportunista, pois convenceu os governantes de épocas de grandes crises políticas e econômicas, de grande depressão, a adotarem sua política intervencionista (RAMALHO, 2016).

Cabe salientar que, à época, os governantes seguiram suas ideias tendo em vista que parecia ser a coisa certa a fazer, tendo em vista que almejavam recuperar a economia em busca do pleno emprego, que deveria ser alcançado, como comentado alhures, com o equilíbrio entre a demanda e a capacidade de produção, equilíbrio este que só seria alcançado com a forte intervenção do Estado na economia (RAMALHO, 2016).

O liberalismo de Hayek é indiscutível. Sua profunda devoção pela liberdade de escolha, pela força do consumidor, só poderia se coadunar com uma equilibrada, porém firme 
liberdade econômica. Para o economista, a planificação econômica centralizada (leia-se intervencionismo), seria pensamento eminentemente construtivista que não poderia dar certo. Por este pensamento intervencionista total, o Estado controlaria toda a produção, do bem menor ao de maior valor, estabelecendo, inclusive a conveniência e o momento que considerasse ideal para sua produção (RAMALHO, 2016).

O grande problema para a planificação econômica centralizada, explicaria Hayek (RAMALHO, 2016), é que desta forma não haveria concorrência e é a concorrência que gera eficiência e inovação, pois é, na verdade, a concorrência, que interfere no preço e produção do mercado, ditadas pelas preferências e exigências do consumidor.

Em outras palavras, para o austríaco, a distorção da intervenção do Estado pode igualmente trazer uma distorção perigosa no conhecimento e nos resultados que os preços transmitem. Assim, de uma forma generalizada, o economista austríaco rejeita a ideia de economia fundada em bases coletivistas, prestigiando, de um modo geral, o aspecto da liberdade em detrimento daquela (RAMALHO, 2016). Ainda segundo Ramalho (2016, Online):

\footnotetext{
Keynes era contrário à nacionalização de toda a economia, mas considerava papel do governo estimular o crescimento desta. Ele argumentava que a única saída para a espiral descendente de desemprego e baixo consumo era uma intervenção governamental de larga escala e com gastos públicos. Foi contra-argumentado pelo austríaco de que a medida traria inflação e que os ajustes eram uma parte inevitável do ciclo de negócios e que os preços deveriam flutuar sem interferência. Além disso, as distorções nos preços geradas pelas intervenções sugeridas por Keynes resultaria em coisas erradas sendo produzidas em quantidades erradas no tempo errado.
}

Até os dias atuais o debate sobre o acertamento das ideias de Keynes, ou das ideias de Hayek, continua a alimentar as teses acadêmicas tanto de economistas quanto de juristas ao redor do mundo.

\section{O INTERVENCIONISMO DE KEYNES, O LIBERALISMO DE HAYEK E A NOVA ORDEM CONSTITUCIONAL BRASILEIRA}

Coordenando-se as ideias que levam às indagações deste artigo, tem-se o liberalismo e o intervencionismo defendidos pelos economistas comentados alhures, como formas técnicas e economicamente viáveis - de acordo com o pensamento de cada um deles, para se projetar uma economia de sucesso. 
Dir-se-ia, então, que de acordo com a nova ordem constitucional, o modelo de transporte individual - Taxi, representaria uma forma de intervenção do Estado na economia (Estado regulador - intervenção indireta), e o modelo de 'transporte individual - Uber', representaria uma liberdade da iniciativa privada, sem a intervenção indireta do Estado.

Por este norte, mesmo admitindo-se como incontroversas as ideias de Keynes e de Hayek (cada uma delas com sua perspectiva técnica e histórica), é certo que existem intervenções diretas e indiretas do Estado na economia. Sobre o tema, Giovani Clark (2001, p. 33) aduz que:

\begin{abstract}
A intervenção direta é realizada quando o Estado cria as chamadas empresas estatais (empresas públicas e sociedades de economia mista) para atuarem no domínio econômico, como agentes, concorrendo com os particulares ou detendo o monopólio; ou, ainda, quando o Estado cria as agências reguladoras para regularem e fiscalizarem serviços e atividades econômicas. Essa modalidade de intervenção pode ser também denominada Direito Institucional Econômico. Ao versar sobre a intervenção direta no domínio econômico, é possível verificar que o Estado pode seguir dois modelos de atuação: o de Regulador e o de Executor.
\end{abstract}

Quando o Estado age como Regulador, segundo José dos Santos Carvalho Filho (2005, p. 731):

\begin{abstract}
Ele elabora normas, reprime abusos, interfere na iniciativa privada e regula preços e abastecimento. O Estado pode intervir de forma direta na ordem econômica, só podendo fazê-lo, no entanto, em nome da segurança nacional e do interesse coletivo para que não venha a ferir princípios constitucionais como o da liberdade de iniciativa. Atuando como regulador, o Estado impõe normas e mecanismos com o intuito de punir e/ou prevenir condutas abusivas que possam vir a prejudicar a harmonia social. Ao atuar como executor, o Estado exerce atividade econômica. Há uma intervenção direta na economia na qualidade de Estado Empresário. Enquanto executor, o Estado realiza atividades econômicas (estritamente) ou presta algum serviço público, comprometendo-se plenamente com alguma forma de atividade dentro das duas categorias apresentadas. As formas mais comuns de intervenção estatal indireta se manifestam nas modalidades de regulamentação, fiscalização, incentivo e planejamento da atividade econômica.
\end{abstract}

A intervenção direta é regulada pelo artigo 174 da Constituição Federal de 1988:

Art. 174. Como agente normativo e regulador da atividade econômica, o Estado exercerá, na forma da lei, as funções de fiscalização, incentivo e planejamento, sendo este determinante para o setor público e indicativo para o setor privado.

$\S 1^{\circ}$ A lei estabelecerá as diretrizes e bases do planejamento do desenvolvimento nacional equilibrado, o qual incorporará e compatibilizará os planos nacionais e regionais de desenvolvimento.

$\S 2^{\circ}$ A lei apoiará e estimulará o cooperativismo e outras formas de associativismo. $\S 3^{\circ} \mathrm{O}$ Estado favorecerá a organização da atividade garimpeira em cooperativas, levando em conta a proteção do meio ambiente e a promoção econômico-social dos garimpeiros. 
$\S 4^{\circ}$ As cooperativas a que se refere o parágrafo anterior terão prioridade na autorização ou concessão para pesquisa e lavra dos recursos e jazidas de minerais garimpáveis, nas áreas onde estejam atuando, e naquelas fixadas de acordo com o art. 21, XXV, na forma da lei.

Como se pode perceber, pelas diretrizes doutrinárias, constitucionais e infraconstitucionais, o Brasil adota uma forma mista de direcionamento de suas bases econômicas, atuando mais de forma indireta, com regulações, do que propriamente de forma direta, até porque, pela forma direta de intervenções existem balizas constitucionais de definição das possibilidades legais. Ou seja, existem situações de respeito pleno à liberdade de iniciativa, outras de intervenção indireta na economia e outras de intervenção direta.

Nestes termos, com relação ao serviço de Taxi e ao serviço de Uber, estaríamos diante de uma regulação para o primeiro caso e uma liberdade de ação para o segundo caso. Nestes termos, se assim o for, existiriam privilégios legais para o uso do aplicativo Uber, ou estar-se-ia diante de regulamentações mais restritivas em relação ao transporte individual Uber?

\section{A HISTÓRIA DOS APLICATIVOS DE TRANSPORTE PRIVADO E O CASO "UBER"}

Feita a introdução teórica ao tema, cumpre explicar em que consistem os aplicativos de transporte privado, os quais têm, cada vez mais, conquistado a preferência do consumidor brasileiro e se convertido em importante meio de circulação de pessoas e mercadorias.

Em decorrência do grande avanço tecnológico do início deste século no âmbito da fabricação de celulares e "smartphones", diversas empresas passaram a ofertar um serviço até então pouco comum: o compartilhamento de um veículo privado para pessoas desconhecidas. O surgimento destes aplicativos está associado ao conceito de "E-Hailing", que consiste em permitir ao consumidor o "chamamento" de táxis por meio de um aplicativo de celular, e não por meio de uma chamada telefônica (SOLVUS, 2016, Online).

O aplicativo de telefone celular mundialmente conhecido por "Uber" chegou ao mercado inicialmente em 2009, na cidade americana de San Francisco, por iniciativa de seus idealizadores Travis Kalanick e Garret Camp.

A ideia inicial dos fundadores era a de transformar o uso de táxis na cidade, concedendo a opção aos clientes de tomarem os chamados táxis luxuosos, compreendidos em veículos mais confortáveis, os quais eram chamados por meio de um aplicativo de celular 
desenvolvido pelos idealizadores e que eram de propriedade de terceiros - e não da empresa bem como pelo prévio conhecimento do valor da corrida e do próprio trajeto e histórico de avaliação do motorista, aspectos que, posteriormente, foram implementados na plataforma geral trazida ao Brasil e que foi apontada pelo CADE como responsável pelo agressivo crescimento da empresa no país (RAO, 2012, Online).

Em 2012, a empresa decidiu inovar a sua plataforma e utilizou a cidade de Londres como primeira a ter a oferta de táxis comuns, abrindo a plataforma utilizada até então em São Francisco para a mencionada cidade.

Com o sucesso do projeto de Londres, a empresa passou a ampliar sua atuação em diversos mercados mundiais, sempre com a ideia de compartilhar o serviço de transporte privado para terceiros, por meio da tecnologia "E-Hailing", ou seja, pelo uso de smartphones, sem chamadas diretas.

Por volta de 2014, o aplicativo chegou ao Brasil na cidade do Rio de Janeiro, em plataforma livre, por meio de aplicativo disponível para os celulares localizados no país, e passou a ser ofertada em diversos centros urbanos, preponderantemente com maior população (RESENDE; LIMA, 2018). Logo após a sua chegada, o impacto foi tamanho na economia, que estimou-se uma queda de aproximadamente 56\%, entre os anos de 2012 e 2014, na utilização dos convencionais “táxis” (OLIVEIRA; ALMEIDA, 2018, Online).

Estudo do CADE demonstrou graficamente a enorme evolução do aplicativo e a consequente diminuição de utilização de aplicativos e serviços de táxis (RESENDE; LIMA, 2018, p. 19):

Gráfico 1

Evolução da Popularidade da Uber, EasyTaxi e 99Taxis no Brasil, 2014-2017

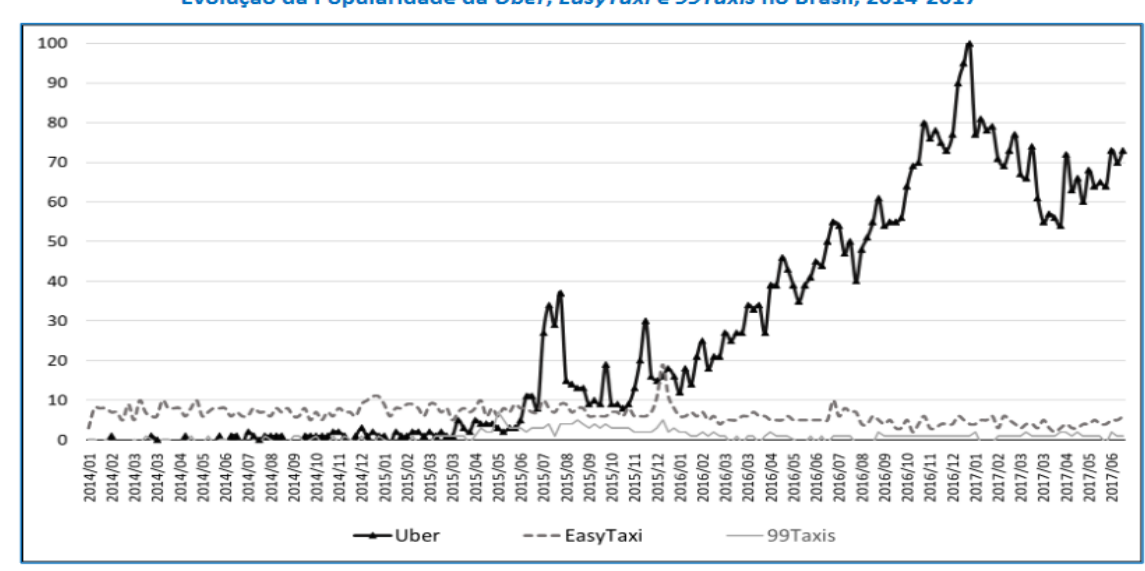


Em razão deste fato, e da enorme rivalidade que surgiu em decorrência da ocupação do mercado pelo aplicativo Uber - e também por outros com plataforma similar, a exemplo de CabifyeEasyTaxi- diversas questões jurídicas foram levantadas, as quais serão enfrentadas no tópico a seguir.

\section{A CELEUMA JURÍDICA EM TORNO DOS APLICATIVOS - A LACUNA DA LEI DE POLÍCIA NACIONAL DE MOBILIDADE URBANA (2012) E AS INICIATIVAS LEGISLATIVAS MUNICIPAIS}

Os taxistas, conforme se expôs, passaram a pressionar os sindicatos, além de diversos setores da sociedade civil como também parlamentares do Congresso Nacional, em razão da crescente perda de mercado em decorrência do avanço da plataforma Uber e seus assimilados.

Dispararam as demandas judiciais que questionavam a possibilidade de o aplicativo se instalar no Brasil sem uma autorização legislativa prévia, ou, no caso da ausência da legislação, sem uma autorização judicial.

Surgiu, então, uma discussão jurídica que se iniciou através da arguida lacuna da Lei 12.587/12, que instituiu as diretrizes da Política Nacional de Mobilidade Urbana, e que nada dispôs sobre os aplicativos mencionados, que somente chegaram, a partir da utilização efetiva dos serviços do Uber, no ano de 2014 no Brasil.

As demandas judiciais que se iniciaram tinham diversos focos, desde aquelas encaeçadas por taxistas - que questionavam a possibilidade de o aplicativo funcionar sem autorização legal e sem ordem judicial autorizativa - até ações que tinham por objeto o reconhecimento de vínculo trabalhista entre a empresa Uber e os motoristas (aspecto que foge à abordagem deste trabalho) bem como situações tributárias, na medida em que o aplicativo não recolhia o Imposto Sobre Serviços - ISS (problemática também não afeta ao tema deste trabalho).

Os problemas que surgiram não se limitaram às demandas judiciais, havendo, por outro lado, diversos problemas sociais, principalmente ao redor de aeroportos, com diversos relatos de violência recíproca entre motoristas da plataforma Uber e taxistas credenciados e licenciados pelos municípios. 
Retomando o aspecto judicial, a mais comum destas demandas judiciais era realizada pelos próprios motoristas de Uber, os quais reclamaram, com base no princípio da livre iniciativa, o direito de exercer uma atividade que dessa possibilidade de garantirem o próprio sustento.

Invocava-se, então, precisamente o princípio estabelecido no art. 170, da Constituição Federal, conforme já se pontuou no início deste trabalho, onde o constituinte garantiu que "a ordem econômica" estaria "fundada na valorização do trabalho humano e na livre iniciativa".

Diversas ordens judiciais foram deferidas no período, mas havia uma imensa insegurança jurídica, não apenas de motoristas da plataforma, mas também de consumidores que utilizavam o recurso e que acabavam por se sentir marginalizados pelo fato de escolherem utilizar um serviço alegadamente não regulamentado.

Daí passou a surgir às primeiras inovações legislativas, que ingressaram na ordem jurídica brasileira no campo da legislação municipal, com base na competência legiferante emanada do art. 30, I, da Constituição Federal: “Art. 30. Compete aos Municípios: I - legislar sobre assuntos de interesse local."

Nesta fase, com base nesta competência, diversos Municípios permitiram o ingresso dos serviços do Uber, com algumas limitações específicas. A primeira cidade do país a promover tal feito foi São Paulo, conforme a Uber (2018, Online):

São Paulo (SP) foi a primeira cidade a regulamentar o serviço no país. Em maio de 2016 a Prefeitura publicou o Decreto 58.981/16 que regulamentou o transporte individual privado no município. A regulação paulistana foi moderna ao criar o conceito de OTTCs (Empresas Operadoras de Tecnologia de Transporte) e ao não limitar a quantidade de veículos ou motoristas, mas a cobrança de contribuição municipal por meio de créditos por $\mathrm{km}$ tem se mostrado de extrema complexidade e de difícil operacionalização. No mesmo sentido, as obrigações de compartilhamento de dados com a prefeitura colidem com a proteção à privacidade de usuários e motoristas determinados pelo Marco Civil da Internet. Regulações posteriores, como a Resolução 16, adicionaram ainda regras contraditórias e uma enorme burocracia para parceiros poderem gerar renda, sem qualquer ganho efetivo para usuários, impondo cobranças e taxas antes mesmo que motoristas comecem a dirigir. A resolução também proibiu carros com placas de outros municípios, medida suspensa pela Justiça por ser considerada inconstitucional. 
No mesmo sentido, outras cidades também criaram a regulamentação de tal serviço, como, por exemplo, Brasília ${ }^{4}$, São José dos Campos $^{5}$, Curitiba ${ }^{6}$, Vitória ${ }^{7}$, Belo Horizonte ${ }^{8}$, Osasco e Campinas 9 .

\begin{abstract}
${ }^{4}$ Conforme Uber (2018, Online): "Brasília (DF) foi a primeira regulação a se consolidar por meio de lei, a Lei Distrital 5.691/16. O texto final foi resultado de um debate bastante polarizado e estabeleceu três camadas de autorização (motorista, OTTC e veículo), o que poderia burocratizar demais e o processo. Entretanto, esses pontos foram aperfeiçoados com a complementação da regulação por meio do Decreto 38.258/17. Um ponto inicialmente previsto na regulação que criava camada de restrição era a limitação da idade dos veículos em 5 anos. Entretanto, após perceber que isso impactava negativamente a oferta do serviço em áreas periféricas, a Câmara alterou para 8 anos esse limite. Apesar da regulação prever grande volume de informações necessárias para que motoristas se cadastrem no sistema, a Secretaria de Mobilidade publicou portarias de proteção aos dados para garantir a privacidade de usuários e motoristas".
\end{abstract}

${ }^{5}$ Conforme Uber (2018, Online): "São José dos Campos (SP) foi a primeira cidade do interior de São Paulo a criar uma regulação moderna para intermediação digital e compartilhamento de carros por meio da tecnologia. $\mathrm{O}$ Decreto 17.462/17 reforçou o papel de polo inovador da cidade, sede da Embraer - parceira da Uber no projeto Elevate. A regulação não impõe restrições e burocracias desnecessárias ao modelo e estabeleceu a cobrança de preço público de $1 \%$ sobre o valor da viagem, gerando nova fonte de receita para o poder público investir em projetos de mobilidade".

${ }^{6}$ Conforme Uber (2018, Online): "Conhecida por sua inovadora rede de transporte público, Curitiba (PR) deu passo importante para a regulação da mobilidade urbana compartilhada com o Decreto 1.302/17 e a Resolução SMF $N^{\circ} 3 / 17$. As empresas de aplicativos passaram a ser tratadas como ATTCs (Administradoras de Tecnologia em Transporte Compartilhado) e foi definido um modelo de preço público decrescente, que diminui proporcionalmente à medida que as distâncias se tornam maiores com o intuito de não sobretaxar a população que vive em regiões mais periféricas da cidade e em geral percorrem distâncias maiores. Mesmo com o incentivo às viagens mais longas, o instrumento configurou nova fonte de receita ao município, que estima arrecadar três vezes mais com aplicativos do que com as taxas cobradas do sistema público de táxis".

${ }^{7}$ Conforme Uber (2018, Online): "Vitória (ES) foi a cidade que melhor entendeu a lógica do sistema. O Decreto 16.770/16 e o Decreto 16.785/16 criaram a regulamentação mais moderna em vigor no Brasil, simplificando regulações que a antecederam e garantindo a eficiência do serviço. A regulação entendeu que esse modelo é fundamentalmente diferente do sistema de transporte individual público (como o táxi), garantiu a privacidade de usuários e motoristas parceiros, e assegurou a liberdade de oferta ao não criar um limite artificial aos carros prestadores do serviço. Além disso, estabeleceu contribuição municipal que consiste em um preço público no valor de $1 \%$ do valor total das viagens realizadas no município".

${ }^{8}$ Conforme Uber (2018, Online): "Belo Horizonte (MG) regulamentou o transporte privado individual por meio do Decreto 16.832/18. A publicação do decreto é um passo na direção de uma regulação moderna, pois estabelece diretrizes gerais para a atuação dos aplicativos de mobilidade na cidade, sem impor restrições. A cobrança de preço público equivalente a $1 \%$ sobre o valor da viagem, por exemplo, seria uma forma justa e equilibrada de remuneração, já que taxa os aplicativos pela sua produtividade. É importante reiterar que as portarias complementares ao decreto precisam seguir um modelo sem burocracias desnecessárias para não inviabilizar o sistema".

${ }^{9}$ Conforme Uber (2018, Online):“Cidade vizinha a São Paulo, Osasco (SP) compreendeu a lógica da flexibilidade de plataformas de tecnologia como a Uber. A Lei 4.850/17 replicou algumas das bem sucedidas políticas apresentadas em Vitória, por exemplo, e aprimorou os desequilíbrios percebidos na regulamentação da capital paulista, reduzindo de forma significativa a burocracia para o acesso de motoristas aos aplicativos. O debate sobre a regulação dos aplicativos em Campinas (SP) ocorreu até ser fixado por meio da Lei 15.539/17 e regulamentações posteriores. Entre os avanços da lei estão o estímulo à presença do serviço em todas as regiões da cidade e a permissão do uso de carros com até oito anos de fabricação. À luz da Lei Federal que regulamenta os transportes por aplicativos, Campinas avançou ao publicar a Resolução $\mathrm{N}^{\circ}$ 84/2018, a qual simplifica as exigências para cadastramento de empresas e motoristas, deixando de impor exigências que foram rejeitadas pelo 
Diversos Municípios, contudo, proibiam a utilização do aplicativo, pelo que tais leis proibitivas chegavam aos Tribunais sob o questionamento de inconstitucionalidade, por ferir o princípio da livre iniciativa, a livre concorrência, e o livre exercício de trabalho ou profissão.

Somente em 2018, com a edição da Lei 13.640/18, que alterou a Lei da Polícia Nacional de Mobilidade Urbana, o tema foi regulamentado com maior clareza no país, tendo delimitado diversas questões importantes no tema em análise.

Em primeiro lugar, a lei definiu esta forma de transporte, agora denominada "transporte remunerado privado individual de passageiros" que deve ser conceituado como sendo um serviço remunerado de transporte de passageiros, não aberto ao público, para a realização de viagens individualizadas ou compartilhadas, solicitadas exclusivamente por usuários previamente cadastrados em aplicativos ou outras plataformas de comunicação em rede.

Em segundo lugar, a lei definiu que cabe aos Municípios a regulamentação dos serviços de Uber, na qualidade de transporte individual de passageiros, diferente das regras específicas dos serviços de táxi, determinando, como regramentos mínimos:

i. que tais serviços de transporte por aplicativos fossem prestados com eficiência, eficácia, segurança e efetividade;

ii. que fosse realizada e efetivada a cobrança dos tributos municipais devidos pela prestação do serviço (ISS e taxas);

iii. que fosse obrigatória a contratação de seguro de Acidentes Pessoais a Passageiros (APP) e do Seguro Obrigatório de Danos Pessoais causados por Veículos Automotores de Vias Terrestres (DPVAT);

iv. que o motorista do transporte Urber fosse inscrito como contribuinte individual do INSS (art. 11, V, “h”, da Lei nº 8.213/91).

Congresso, como a necessidade de autorização específica, a proibição de carros emplacados em outro município e a obrigação de que o condutor seja proprietário do veículo. Ficam como pontos problemáticos da regulação a possibilidade de acesso a informações de motoristas e veículos pela internet - o que fere a privacidade e a confidencialidade de dados pessoais - e um modelo de identificação visual muito pouco prático e seguro, que não oferece benefícios para motoristas ou usuários. O Rio de Janeiro (RJ) assumiu um papel protagonista em mobilidade urbana com o Decreto 44.399/18, a primeira regulamentação criada depois da Lei Federal 13.640/18 ser sancionada. Ao mesmo tempo em que estipulou regras claras para o transporte individual privado na cidade, o decreto afastou limitações artificiais como o uso de placas restritas para este tipo de serviço - liderando o debate sobre como a tecnologia pode servir melhor as cidades". 
Em terceiro lugar, a lei fez exigências aos motoristas do aplicativo (art. 11-B da Lei de Polícia Nacional de Mobilidade Urbana), a saber:

I - possuir Carteira Nacional de Habilitação na categoria B ou superior que contenha
a informação de que exerce atividade remunerada;II - conduzir veículo que atenda
aos requisitos de idade máxima e às características exigidas pela autoridade de
trânsito e pelo poder público municipal e do Distrito Federal; III - emitir e manter o
Certificado de Registro e Licenciamento de Veículo (CRLV); IV - apresentar
certidão negativa de antecedentes criminais.

A grande questão que se coloca a partir do debate iniciado com este trabalho é se, após a Lei número 13.640/18, não havendo regulamentação pelo Município específico, o serviço Uber poderia funcionar no país.

Entende-se que, com base na teoria de Hayek, o Estado não deve intervir na Economia senão de forma a regulamentar seus aspectos de funcionamento legal - tal como se exigiu pela Lei 13.640/18 - não cabendo ao Estado proibir eventual prática ou serviço, quando não há regulamentação.

Em outras palavras, nos Municípios onde não há regulamentação do aplicativo Uber, é de se reconhecer a legalidade do fornecimento do serviço, com base nos princípios da livre iniciativa e da livre concorrência (art. 170, da Constituição Federal).

\section{CONCLUSÃO}

Este estudo abordou alguns aspectos relacionados ao "transporte remunerado privado individual de passageiros", com foco no aplicativo Uber, examinando aspectos de teoria econômica, sobre a evolução histórica do aplicativo, bem como as diversas controvérsias surgidas durante sua breve história no Brasil.

Restou clarificado que, mesmo admitindo-se como incontroversas as ideias de Keynes e de Hayek, é certo que existem intervenções diretas e indiretas do Estado na economia Brasileira.

Poder-se-ia afirmar que o Brasil adota uma forma mista de direcionamento de suas bases econômicas, atuando mais de forma indireta, por meio de regulações, do que de forma direta. 
E, justamente, por causa dessa caraterística mista, é que surgiu toda a polêmica acerca do uso do aplicativo Uber e sua falta de regulamentação quando comparada aos serviços semelhantes oferecidos pelos taxis.

A falta de legislação sobre a temática causava dúvidas acerca da possibilidade de oferecimento deste tipo de serviço (Uber - transporte privado e individual de passageiros) para os consumidores, dúvidas essas que abarrotavam o Poder Judiciário em busca de uma solução que se identificasse com os fatos sociais emergentes e com as políticas públicas de intervencionismo na iniciativa privada com o caráter meramente regulamentador.

Geralmente as decisões e sentenças judiciais se apresentavam no sentido de permitir a utilização de tal aplicativo, amparadas na disposição inserta no artigo 170 do Texto Constitucional.

Entretanto, a insegurança jurídica sobre a questão ainda era grande e assim, aos poucos, cada município passou a regulamentar, a seu modo, o oferecimento dos serviços da UBER.

Entende-se que a Lei 13.640/18 trouxe uma grande contribuição para o tema, fixando balizas mínimas de funcionamento do aplicativo, a exemplo de questões de segurança de trânsito, segurança no transporte, questões tributárias e previdenciárias.

Porém, não se pode olvidar que, com base no princípio da livre iniciativa e da livre concorrência, não havendo regulamentação em Municípios, pode o aplicativo funcionar normalmente, não podendo a mora regulamentar de um governo municipal prejudicar consumidores e usuários gerais da plataforma.

Não se podem abandonar, no afã de novas conquistas políticas e econômicas, as lições de clássicos sociólogos da estirpe de Durkheim (2002) que defendem o destaque das escolhas individuais legitimadas por fatos sociais incontestáveis, com a força de criação de regras e regulamentações que visem à mantença da ordem social e econômica de uma sociedade política ${ }^{10}$.

\footnotetext{
${ }^{10}$ Neste sentido, Durkheim (2002, p. 79), afirma que "quanto mais avançamos na história, mais vemos as coisas mudarem. Antes perdida no seio da massa social, a personalidade individual se destaca dela. O círculo da vida individual, antes restrito e pouco respeitado, amplia-se e torna-se o objeto eminente do respeito moral. $\mathrm{O}$ indivíduo adquire direitos cada vez mais extensos a dispor de si mesmos, das coisas que lhe são atribuídas, a se fazer do mundo as representações que lhe pareçam mais convenientes, a desenvolver livremente sua natureza".
} 
A conquista da iniciativa privada pela regulamentação de empresa de transporte 'público' individual, tradicionalmente representativa de um serviço de concessão do Estado, demonstra sem sombra de dúvida que o Estado "vai se desenvolvendo cada vez mais; por outro lado, os direitos do indivíduo que são vistos como opostos aos direitos do Estado se desenvolvem paralelamente" (DURKHEIM, 2002, p. 80), de sorte a sermos hoje, a despeito do eventual intervencionismo do Estado, pessoas "muito mais livres em meio a uma multidão do que num pequeno grupo" (DURKHEIM, 2002, p. 85), quando, através do fato real, o Estado é compelido a regulamentar a fim de garantir o necessário equilíbrio entre o interesse público e a necessidade da regulação privada.

\section{REFERÊNCIAS}

BRASIL. Constituição (1988). Constituição de 1988. Brasília, Disponível em: http://www.planalto.gov.br/ccivil_03/constituicao/constituicaocompilado.htm. Acesso em: 12 mar. 2018.

BRASIL. Lei n ${ }^{\circ}$ 12.587, de 03 de janeiro de 2012. Diretrizes da Política Nacional de Mobilidade Urbana. Brasília , 04 jan. 2012. Disponível em: http://www.planalto.gov.br/ccivil_03/_Ato2011-2014/2012/Lei/L12587.htm. Acesso em: 14 mar. 2019.

BRASIL. Lei $\mathrm{n}^{\circ}$ 13.640, de 26 de março de 2018. Regulamento do Transporte Remunerado Privado Individual de Passageiros. Brasília, 27 mar. 2018. Disponível em: http://www.planalto.gov.br/ccivil_03/_Ato2015-2018/2018/Lei/L13640.htm. Acesso em: 14 mar. 2019.

CARVAlHO FILHO, José dos Santos. Manual de Direito Administrativo. 16. ed. Rio de Janeiro: Lúmen Júris, 2005.

CLARK, Giovani. O Município em face do Direito Econômico. Belo Horizonte: Del Rey,2001.

DURKHEIM, Emile. Lições de Sociologia. São Paulo: Martins Fontes, 2002. Disponível em: https://edisciplinas.usp.br/pluginfile.php/4261069/mod_resource/content/1/Emile\%20Durkhei m\%20-\%20Li\%C3\%A7\%C3\%B5es\%20de\%20Sociologia.pdf. Acesso em: 03 abr. 2019

JESUS, Jorge Miguel Cardoso Ribeiro de. A ECONOMIA DE JOHN MAYNARD KEYNES: UMA PEQUENA INTRODUÇÃO. Textos de Economia, Florianópolis, v. 14, n. 1, p.118-137, jun. 2011. Disponível em:

https://www.google.com/url?sa=t\&rct=j\&q=\&esrc=s\&source=web\&cd=1\&ved=2ahUKEwi T z5OkppXfAhULE5AKHTm6CLgQFjAAegQICRAC\&url=https\%3A\%2F\%2Fperiodicos.ufsc .br\%2Findex.php\%2Feconomia\%2Farticle\%2Fdownload\%2F2175- 
8085.2011v14n1p118\%2F21686\&usg=AOvVaw1gyRGnYOV2sNzdTWVHX0V3. Acesso em: 13 mar. 2019.

OLIVEIRA, Paulo; ALMEIDA, Neila. Chegada do Uber ao Brasil reduziu mais da metade das corridas de aplicativos de táxi, conclui estudo. 2018. Disponível em:

https://economia.estadao.com.br/noticias/geral,chegada-do-uber-ao-brasil-reduziu-mais-dametade-das-corridas-de-aplicativos-de-taxi-conclui-estudo,70002265737. Acesso em: 14 mar. 2019.

RAMALHO, Tiago Rego. O conceito de Liberdade no pensamento de Friedrich Hayek. Covilhã: Lusosofia Press, 2016. Disponível em: http://www.lusosofia.net/textos/20160114-ramalho_tiago_2016_conceito_liberdade.pdf. Acesso em: 14 mar. 2019.

RAO, Leena. Uber Brings Its Disruptive Car Service To Chicago. 2012. Disponível em: https://techcrunch.com/2011/09/22/uber-brings-its-disruptive-car-service-to-chicago/. Acesso em: 14 mar. 2019.

RESENDE, Guilherme Mendes; LIMA, Ricardo Carvalho de Andrade. Efeitos concorrenciais da economia do compartilhamento do Brasil: A entrada do uber afetou o mercado de aplicativos de táxi entre 2014 e 2016?. 2018. Disponível em:

http://www.cade.gov.br/acesso-a-informacao/publicacoes-institucionais/dee-publicacoesanexos/documento-de-trabalho-001-2018-uber.pdf. Acesso em: 14 mar. 2019.

SOLVUS (Org.). Conheça agora 4 empresas que mudaram o mundo com aplicativos. 2016. Disponível em: http://solvus.com.br/conheca-agora-4-empresas-quemudaram-o-mundo-com-aplicativos-4//. Acesso em: 13 mar. 2019.

UBER. Como o transporte individual privado por aplicativos tem sido regulamentado no Brasil. 2018. Disponível em: https://www.uber.com/pt-BR/newsroom/transporte-individualprivado-aplicativos-regulamentado-brasil/. Acesso em: 14 mar. 2019. 